\title{
Access to Green Space and Median Household Income in Metro Vancouver Cities
}

\section{David Luo ${ }^{1}$, Helen Heacock ${ }^{2}$}

1. Lead Author, B.Tech Student, School of Health Science, British Columbia Institute of Technology, 3700 Willingdon Ave, Burnaby BC, V5G3H2

2. Supervisor, School of Health Science, British Columbia Institute of Technology, 3700 Willingdon Ave, Burnaby BC, V5G3H2

\begin{abstract}
Background: Greenspace is a very important component of a healthy built environment. It can provide many benefits which include mitigating the effects of climate change, improving air quality, and enhancing mental and physical health. However, it has been shown that health promoting resources such as green spaces are often unequally distributed among different socioeconomic classes. The objective of this study was to identify disparities in proportional greenspace access between different income categories among the residents of three cities in Metro Vancouver, British Columbia. The mapping tool ArcGIS was used to visualize patterns of greenspace distribution and median household income.
\end{abstract}

Methods: Green space was classified as recreational parks within the cities of New Westminster, Vancouver and Burnaby in Metro Vancouver. Income and green space data were gathered from Statistics Canada and the Municipalities' websites for mapping in ArcGIS respectively. This data was then exported, and a correlation analysis was performed to identify any relationship between green space and median household income of census tract divisions.

Results:_Out of 248 data points, 90 census tracts were analyzed in Burnaby, 145 in Vancouver and 13 in New Westminster. Patterns in the maps indicated that higher income census tracts had lower proportional access to green space. Statistical results demonstrated that a negative correlation exists between greenspace and median household income. Higher income households have less access to green space across all three Metro Vancouver cities; New Westminster ( $p=$ $0.33)$, Vancouver $(p=0.02)$ and Burnaby $(p=0.03)$ a negative correlation was also found in a combined analysis across all three cities $(\mathrm{p}=0.0013)$. 
Conclusion: Green space is undeniably important to all individuals within a city as it can provide recreational opportunities, improve physical and mental health, temper climate change, improve air quality and provide cooling effects. There may be substitutes to recreational activities that green space can provide, but there are none for the overall benefits that it can provide. This study calls for policy makers and planners to consider greater investments in green space and recreational parks in all census tracts including wealthier neighbourhoods, where smaller proportions of greenspace were identified. Programs such as the City of Vancouver's "Greenest City Action Plan" whose goal is to encourage green initiatives including situating all residents within a five minute distance of greenspace should be implemented across all three cities.

Keywords: Greenspace, income, median income, recreational park, ArcGIS 


\section{Introduction}

Having a physically active lifestyle is beneficial to preventing chronic disease, promoting mental health and generally leading to better health outcomes. (CDC, 2014) One of the barriers to physical activity is a lack of recreational facilities and green space. (Gilmour, 2007) Low income households are further impacted due a lack of financial means to pay for recreational activities such as gym memberships or water related activities. There is a great disparity in health outcomes between low and high income households. (Lemstra et al 2006) A lack of green space may increase that disparity, therefore free recreational space or urban parks is of great importance to low income households. Ease of access to greenspace will eliminate one of the essential barriers to physical activity. Having large greenspace areas in all neighborhoods can provide low income households an opportunity for jogging, walking, cycling, and other outdoor recreational activities thereby reducing the disparity between physical activity and health. (S.L. Handy et al 2002) Furthermore, it will help fight obesity due to a lack of exercise; an increasing problem in the developed world.
The City of Vancouver has current green goal initiatives called the "2020 Greenest Action Plan" One of the ten goals of this plan is to situate each resident within a fiveminute walking distance to an urban park or other green space. (Greenest City: 2020 Action Plan, 2014). Other green space can include parks and fields, greenways, the seawall, street miniparks, natural greenspaces as well as park-like spaces such as around hospitals, City halls and schools. (Greenest City: 2020 Action Plan, 2014). This current plan is a good initiative, but it does not guarantee residents a good quality of green space like a big urban park. The author of this article was interested in comparing the quantity of urban parks to the relative income of the households in three Metro-Vancouver Cities to assess relationships between household income and proportional greenspace by census tract.

\section{Literature Review}

\section{Green space and Health}

Green space such as recreational parks and sport fields are an essential part of any urban development providing residents of neighbourhood opportunities for exercise and relaxation. Having access to green space can reduce health inequities, improve 
wellbeing and mental health (WHO, 2016).

According to Bowler et al (2010), the

natural environment such as urban park

space potentially has a direct and positive

effect on wellbeing. Green space may be an important environmental determinant of health for the residents of neighbourhoods. Many studies have shown the benefits of greenspace to general health. For example, greenspace promotes exercise and decreases the risk of cardiovascular disease and poor mental health independent of individual risk factors. (Richardson et al 2013). Green space offers a combination of exposure to nature and exercise and can be a powerful tool to fight physical inactivity and noncommunicable diseases. (Gladwell et al 2013)

Greenspace has environmental benefits that could potentially affect health outcomes. It can absorb air pollutants, absorb heat, and provide natural sights for relaxation purposes. A Canadian study highlighted the growing evidence of more heat and air quality related health burdens associated with disproportionate distribution of greenspace in urban neighbourhoods (Zupancic et al 2015). It was also concluded that the quantity and quality of greenspace should be improved and green strategies should be prioritized for vulnerable populations (Zupancic et al 2015).

\section{Green space, Social-Wellbeing and Mental Health}

Having access to greenspace can promote social wellbeing to people of all ages. It may facilitate interactions that may otherwise not occur in other social settings. Green space can also provide a place of attachment for older adults and a place of interaction for children and adults. The social benefits for individuals who live closer to greenspace is that they tend to be more effective in managing life issues, coping with poverty and performing better in cognitive tasks. (Bell et al 2008) These benefits could be due to the added interactions that occur within greenspace. Therefore, it is important that people, especially those of lower socioeconomic status have sufficient access to greenspace so that they can cope with stress and poverty related issues. Furthermore, green space is equigenic; promoting mental health wellbeing and reducing socioeconomic health inequities. (Barton and Rogerson 2017). Presence of Greenspace encourages social interactions which cultivates social cohesion in a way that improves health and 
wellbeing (Jennings and Bamkole 2019)

Urban green space is also linked to increased social engagement and enhances both psychological and physical wellbeing. (Jennings and Bamkole 2019).

\section{Green space and Physical activity}

The main benefit from having Green Space is the recreational space availability offered for people to participate in physical activity. The health benefits of physical activity has been established. Estimates using data based in the Canadian Community Health Survey shows that participation in physical activity can reduce the incidence of diabetes, high blood pressure, heart disease, asthma and arthritis. (Humphreys et al 2014). The ease of access to physical activity has also been studied extensively and linked to performing physical activity. Access to sports facilities or recreational space to exercise is positively associated with doing physical activity. (Lee at al 2016). As a result, ease of access to recreational areas can encourage people to exercise. Readily available green space and recreational parks is able to provide this access if there is enough recreational space situated close to where residents live. Previous research has suggested that the link in health outcomes and green space is due to increased physical activity levels for people living in areas with more green space. (Mytton et al 2012) Furthermore, this study demonstrated a positive association between green space and exercise. (Mytton et al 2012). However, Mytton concluded that the study did not explain why green space contributed to this and what type of physical activity people do in the greenspace.

\section{Green space and Income}

Differences in the available recreational areas may contribute to disparities in physical activity among low and high socioeconomic status and thereby affect health outcomes. (Moore et al 2008) Statistics Canada identified that in 2015, only $76 \%$ of low-income households had a park close to home; however, in 2017, this percentage increased to $83 \%$. In comparison, 95\% of high income households had a park close to home in 2017. (Statistics Canada, 2017) The availability of parks and free green space that provides opportunities for exercise may promote a healthier and more active lifestyle. However, this may be hindered by the socioeconomic status of the population.

\section{Proportion of Green Space and Income}


One of the most important socioeconomic factors that affect accessibility to resources is income. Wealthier people tend to be able to afford homes with better accessibility to valuable resources like green space, transit and commercial buildings. Furthermore, wealthier people tend to have access to a higher proportion of these things. According to Nesbitt, wealthier neighbourhoods are located closer to larger green areas like Pacific Spirit Park and Stanley Park in the City of Vancouver. A study by Nesbitt found that income and education have a positive correlation to urban distribution of greenspace across most cities in the US. (Nesbitt et al 2019) This means that people who are less privileged have less proportional access to green space. However, she did not include any Canadian cities in her research. With Metro Vancouver's growing population, the amount or proportion of green space available is becoming increasingly important. As the population and the city grow, people will move to areas with fewer resources due to gentrification. The City of Vancouver has established a goal to get each and every resident within a five-minute walking distance to a park, greenway or greenspace area by the year 2020 . At the time of publishing this paper, Vancouver has not made much headway with this initiative, only increasing greenspace by $0.1 \%$ from $92.7 \%$ to $92.8 \%$ in the past decade (https://vancouver.ca/greenvancouver/access-to-nature.aspx\#naturemeasurement). However, the quality and quantity of greenspace is not specified. Therefore, it is also important to look at the proportion of greenspace in each neighbourhood to determine if there are sufficient urban parks in each area for each resident.

\section{ArcGIS in Public Health}

Geographic Information Systems, more commonly known as GIS is a useful tool that can provide a spatial visualization of integrated data. Public health uses of GIS include tracking child immunization, conducting health research and looking at disease distribution. It was used in a previous study to determine visible minority proportion and green space access. (Luo et al 2018)

\section{Purpose of Study}

To the author's knowledge, there has not been any research assessing the proportion of greenspace within MetroVancouver relative to the income of the neighbourhood. Therefore, the objective of 
this study was to examine whether there are disparities in proportional greenspace access between different income categories in the residents of Metro Vancouver. The findings in this research can help municipalities of Metro-Vancouver shape their community development planning ensuring access of green space to all residents regardless of socioeconomic status, thereby reducing disparities in physical activity and health.

\section{Methods}

\section{Variables}

Median Household income and proportional greenspace were the variables of interest in this research. Green space was defined as urban parks within Metro Vancouver as they represent good quality greenspace for the purpose of recreational use and physical activity. Proportional greenspace was obtained by dividing the census tract area by park area in ArcGIS. Data was collected, and secondary data analysis was carried out. Two maps were generated using ArcGIS showing distribution of income and greenspace. Data was collected in the sources depicted in Table 1.

\section{Study Area}

Census tracts within three Metro Vancouver municipalities were chosen to be analyzed (Vancouver, Burnaby, and New Westminster). The three municipalities were chosen because existing Metro Vancouver GIS maps have shown that the areas are close in proximity and are more urban compared to municipalities such as Delta, Surrey and Coquitlam. In addition, it is important to evaluate and put in recommendations to the greenest city action plan for the city of Vancouver. (https://vancouver.ca/greenvancouver/greenest-city-action-plan.aspx). Cities other than Vancouver do not have similar initiatives so it would be interesting to assess how green space is distributed in those cities. Since the study area of interest were the three municipalities within Metro Vancouver, it was determined to use census tract data and not dissemination area to measure larger areas. Census tracts are geographic areas that are separated based on populations of approximately 10,000 people whereas dissemination areas are the geographical units separated by area that consists of small populations of 400 to 700 people (Stats Canada, 2016).

\section{Data Collection and Procedures}


Data from various sources were collected to create the map. The 2016 Census tract shapefile with income for Vancouver metropolitan area was downloaded from Statistics Canada using the application "Computing in the Humanities and Social Sciences" (Stats Canada, 2016). Then, the Municipal boundary data was downloaded from http://www.metrovancouver.org/data. Very lastly, the park shapefiles were collected from each city's municipality website. City of Vancouver: https://data.vancouver.ca/datacatalogue/park Listing.htm, City of Burnaby: https://data.burnaby.ca/datasets/parkinventory, and City of New Westminster: http://opendata.newwestcity.ca/datasets/park s-greenspaces. ArcGIS Mapping (Luo et al , 2018)

The first map created was a green space distribution map of the three municipalities. The second map created was a median household income distribution map of the three municipalities. This was created by using two types of data; the 2016 census tract boundary or geography of Metro Vancouver and the census tract median income by household family from Statistics Canada using the Canadian Census Analyser of CHASS. (Statistics Canada, 2016)

\section{Statistical Analysis: Correlational Test using Regression}

The median household income per census tract data and Greenspace per census tract data was joined together onto a single attribute table on ArcGIS. Park proportion was calculated by dividing park area over the respective census area. The join resulted in 253 data points with green space proportions corresponding to the income in each census tract of all three cities. This data was then exported from the attribute table from GIS to an excel file in order to perform a correlational test on NCSS. The Pearson's correlation test was used to identify the relationship between greenspace proportion and median household income, with the acceptable significance value of $p<0.05$. A total of 253 census tracts containing data was recorded from the three cities. There were three census tracts in Burnaby, one in New Westminster that had a park area bigger than the census area. GIS calculated the proportion to be much greater than one which resulted in outliers. Furthermore, there was one census tract in Vancouver that was missing median income data. Therefore, these five points of data were excluded from the study leaving 248 census tracts for analysis. Out of the 248 data points, 90 census tracts were analyzed in Burnaby, 145 
in Vancouver and 13 in New Westminster. This is depicted in the pie chart below.

\section{Figure 1.}

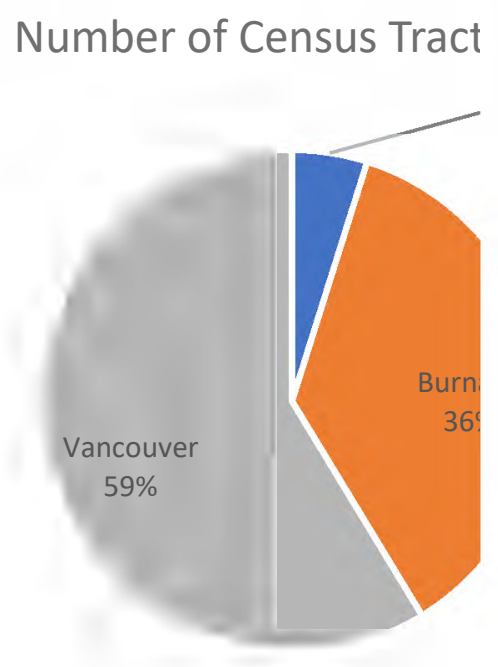

\section{Results}

\section{Map discussion}

The general pattern found in the map

generated was that the higher median

income census tracts had lower green space

proportions situated in their respective areas.
The map depicts that the median household income within most of west and central Vancouver is above $\$ 84,480$. However, many of these census areas have a proportional greenspace access of less than 0.0057 . This is particularly visible in the central west area of Vancouver. In addition, the downtown area had lower median income overall but had more proportional green space access. This could be due to the fact that the downtown area has smaller census tracts which means the parks in the area could significantly boost the proportions of greenspace. The same general pattern can be seen in the City of Burnaby. The areas in central Burnaby lacked green space proportions but the median household income was found to be above $\$ 84,480$.

Similar results can be found in New

Westminster, where higher income resulted in less proportion of greenspace. 
Map 1

Map of Park Proportions In Vancouver, New West and Burnaby by Census Tract

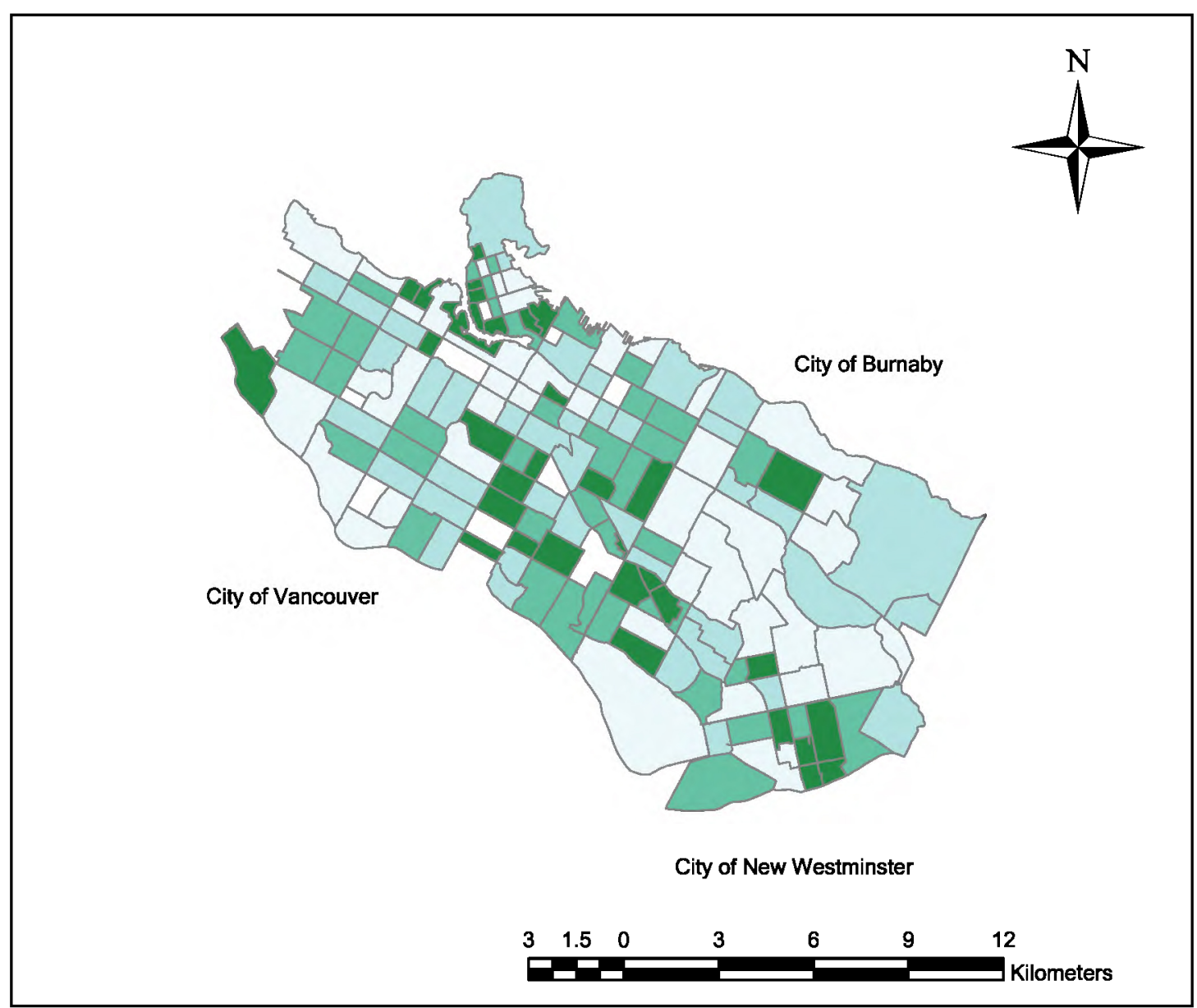

Parks Vancouver, New West, Burnaby Proportions over Census Tract Area

\begin{tabular}{|l|l|}
\hline & $\leq .0022218$ \\
\hline & $\leq .0057495$ \\
\hline & $\leq .0103780$ \\
\hline & $\leq .0180959$ \\
& $\leq .0285002$ \\
& $\leq .0493661$ \\
& $\leq .0998840$ \\
& $\leq 1976.9654541$
\end{tabular}

Map Designer: Yu Ning David Luo 
Map 2

Map of Median Total Household Income In Vancouver, New West and Burnaby By Census Tract

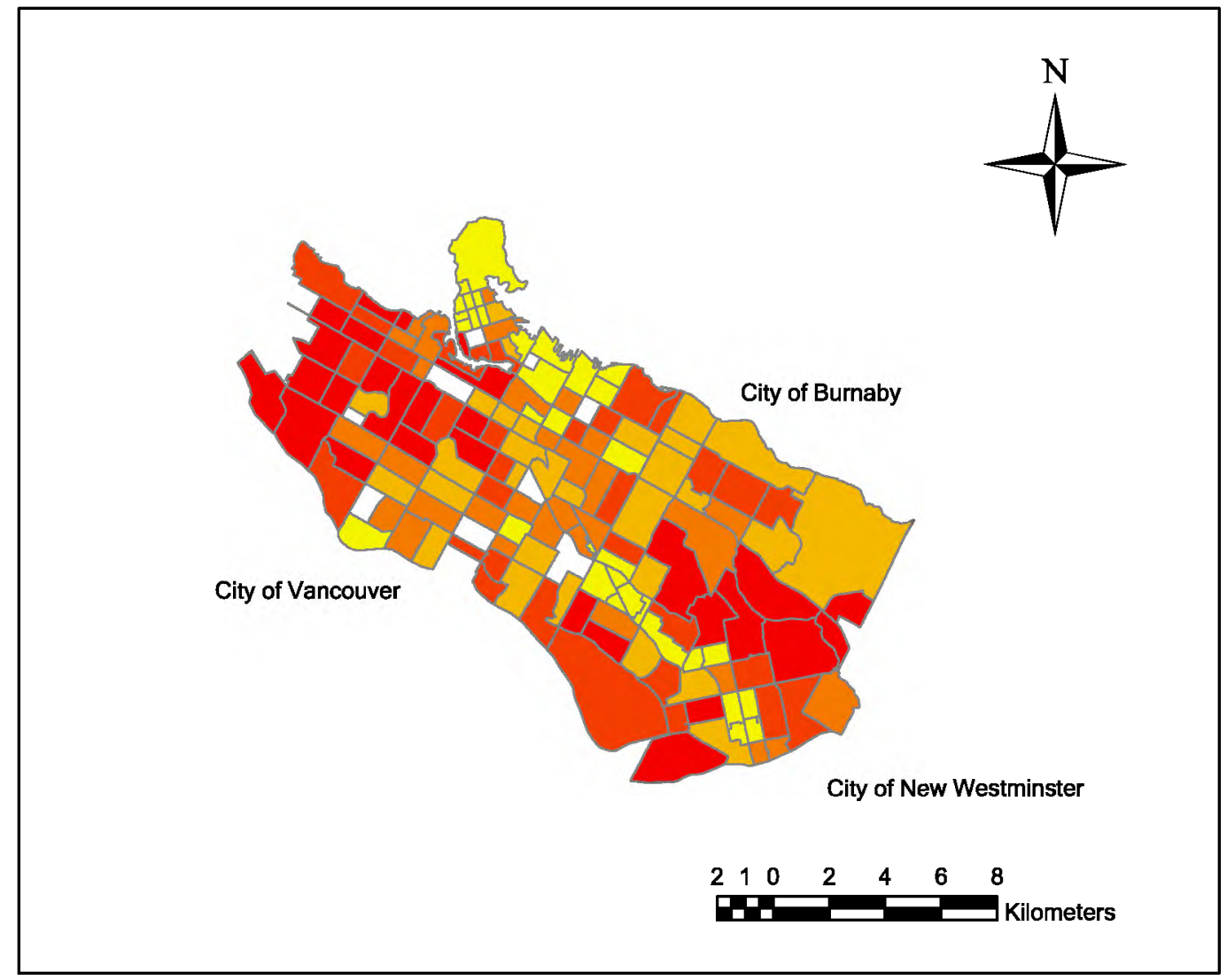

Median Total Household Income in Census Tracts

Median Total Household Income 2015

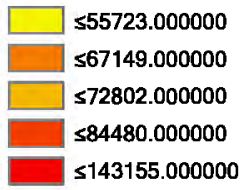

Map Designer: Yu Ning David Luo 


\section{Summary of Statistical Analysis}

\begin{tabular}{|c|c|c|c|}
\hline $\mathrm{H}_{0}$ and $\mathrm{H}_{\mathrm{a}}$ & City Name & Results & Interpretation of Results \\
\hline $\begin{array}{l}\mathrm{H}_{0} \text { : There is no significant correlation } \\
\text { between median household income and } \\
\text { proportional greenspace in Burnaby, } \\
\text { New Westminster and Vancouver } \\
\mathrm{H}_{\mathrm{a}} \text { : There is a significant correlation } \\
\text { between median household income and } \\
\text { proportional greenspace in Burnaby, } \\
\text { New Westminster and Vancouver }\end{array}$ & $\begin{array}{l}\text { Combined } \\
\text { Cities }\end{array}$ & $\begin{array}{l}\mathrm{n}=247 \\
\mathrm{r}=-0.2034 \\
\mathrm{p}=0.0013\end{array}$ & $\begin{array}{l}\text { Reject } \mathrm{H}_{0} \text { and conclude there is a } \\
\text { statistically significant negative } \\
\text { correlation between median } \\
\text { household income and proportion of } \\
\text { greenspace in all } 3 \text { cities. Power = } \\
0.9009\end{array}$ \\
\hline $\begin{array}{l}\mathrm{H}_{0} \text { : There is no significant correlation } \\
\text { between median household income and } \\
\text { proportional greenspace in Vancouver. } \\
\mathrm{H}_{\mathrm{a}} \text { : There is a significant correlation } \\
\text { between median household income and } \\
\text { proportional greenspace in Vancouver }\end{array}$ & Vancouver & $\begin{array}{l}\mathrm{n}=145 \\
\mathrm{r}=-0.1907 \\
\mathrm{p}=0.0216\end{array}$ & $\begin{array}{l}\text { Reject } \mathrm{H}_{0} \text { and concluded there is a } \\
\text { statistically significant negative } \\
\text { correlation between median } \\
\text { household income and proportion of } \\
\text { greenspace in Vancouver. Power = } \\
0.6357 \text { which suggests results may } \\
\text { not be valid. A larger sample size } \\
\text { should reduce beta error and increase } \\
\text { power. As p = } 0.0216 \text {, there is a } \\
\text { possibility for an alpha error. }\end{array}$ \\
\hline $\begin{array}{l}\mathrm{H}_{0} \text { : There is no significant relationship } \\
\text { between median household income } \\
\text { and proportional green space in } \\
\text { Burnaby }\end{array}$ & Burnaby & $\begin{array}{l}\mathrm{n}=90 \\
\mathrm{r}=-0.2330 \\
\mathrm{p}=0.0271\end{array}$ & $\begin{array}{l}\text { Reject } \mathrm{H}_{0} \text { and conclude there is a } \\
\text { statistically significant negative } \\
\text { correlation between median } \\
\text { household income and proportion of }\end{array}$ \\
\hline
\end{tabular}




\begin{tabular}{|c|c|c|c|}
\hline $\begin{array}{l}\mathrm{H}_{\mathrm{a}} \text { : There is a significant correlation } \\
\text { between median household income and } \\
\text { proportional greenspace in Burnaby. }\end{array}$ & & & $\begin{array}{l}\text { greenspace in Burnaby. Power }= \\
0.6039 \text {, which suggests results may } \\
\text { not be valid. A larger sample size } \\
\text { should reduce beta error and increase } \\
\text { power. As } p=0.0271 \text {, there is a } \\
\text { possibility for alpha error. }\end{array}$ \\
\hline $\begin{array}{l}\mathrm{H}_{0} \text { : There is no significant correlation } \\
\text { between median household income and } \\
\text { proportional greenspace in New } \\
\text { Westminster. } \\
\mathrm{H}_{\mathrm{a}} \text { : There is a significant correlation } \\
\text { between median household income and } \\
\text { proportional greenspace in New } \\
\text { Westminster. }\end{array}$ & $\begin{array}{l}\text { New } \\
\text { Westminster }\end{array}$ & $\begin{array}{l}\mathrm{n}=13 \\
\mathrm{r}=-0.2901 \\
\mathrm{p}=0.3301\end{array}$ & $\begin{array}{l}\text { Do not reject } \mathrm{H}_{0} \text { and conclude there } \\
\text { is no significant correlation between } \\
\text { median household income and } \\
\text { proportion of greenspace in New } \\
\text { Westminster. Power = } 0.1512 \text {, which } \\
\text { suggests the results may not be valid. } \\
\text { A larger sample size should reduce } \\
\text { beta error and increase power. }\end{array}$ \\
\hline
\end{tabular}

\section{Statistical Analysis}

All statistical analyses were conducted in NCSS. A combined and separate correlation analysis was performed for all 3 cities; Vancouver, New

Westminster and Burnaby. Table 1 shows the results of the analysis. In the combined analysis, green space proportion was found 
to be negatively correlated to median household income $(\mathrm{r}=-0.2034, \mathrm{p}=0.0013)$. Therefore, $\mathrm{H}_{0}$ was rejected and it was concluded that there was significant correlation between greenspace proportion and income in the three municipalities of interest; Burnaby, New Westminster, and Vancouver. Higher income was correlated with less green space. When the analysis was conducted for each city separately, the same negative correlation was found across all three cities. For the City of Vancouver, the finding was a statistically significant negative correlation $(\mathrm{r}=-0.1907, \mathrm{p}=0.0216)$. A similar correlation resulted for the City of Burnaby $(r=-0.2330, p=0.0271)$. However, when the analysis for New Westminster was conducted, the correlation was still negative, but the finding was not statistically significant. $(\mathrm{r}=-0.2901, \mathrm{p}=0.3301)$. This could be due to a small number of census tracts that exist within New Westminster. $(n=12) . \quad H_{0}$ was rejected for each analysis except New Westminster and it was concluded that there was significant negative correlation between greenspace proportion and median household income.

\section{Discussion}

Previous research has suggested that health promoting resources such as green space are often unequally distributed among varying socioeconomic classes within a population. The results were consistent, and a pattern can be generalized in indicating that lower income and education households had substantially less access to greenspace. (Astell-bert et al ,2014; Nesbitt et al 2019) To the author's knowledge, this is the first time this study has demonstrated that, higher income households had less access to green space. A large body of research has placed emphasis on the social injustice of better green access in wealthier populations. These findings indicate the opposite; suggesting that the availability of green space access is less among the census tracts of higher income neighbourhoods in all three cities; New Westminster, Vancouver and Burnaby. The wealthy may have less need of greenspace near them as they tend to have the financial resources to access privatized greenspace, pursue many different recreational sports, or even travel extensively to areas of green space. However, greenspace access in their own census tract can still affect the health and well-being of wealthier populations as it is shown to temper climate change, improve physical and mental health, mitigate the urban heat island effect by cooling its surroundings, and improve air quality. 
(Kingsley, 2019) If the findings are valid and the economically disadvantaged have more access to green space, this should be beneficial for their emotional and physical health, particularly if finances are a barrier to access health pursuits. However, it is important for everyone including those with higher incomes, to have access to a good proportion of greenspace and the benefits it can potentially provide.

\section{Limitations}

There were several limitations to this study. First, the focus was to find the varying amount of greenspace among different social economic classes, and it cannot be drawn as a conclusion that making more green space available means the utilization of green space among the different social economic classes. The study did not look at whether or not green space is used, only if it exists and its relationship to income. What the study did show is that there is a relationship between income and green space and this is a negative relationship which can be viewed as somewhat positive as those with less income often have less means to participate in sport; hence access to greenspace will give them free access to healthful activity. Second, due to a lack of data, the measure of green space only included recreational parks and did not take into account other types of green space. A limitation of this greenspace measure is that it does not detect any other types of greenspace or green canopy within the cities unless they were inside a park. For example, it is possible that private green space such as golf courses exists within a community and the higher income population utilize that instead of public recreational parks. This study also does not take into account the quality differences of each park. Furthermore, certain parks could have better health promoting features such as well-designed walking trails, big open space for recreational use, playgrounds for children or being more aesthetically pleasing. Third, proximity and proportion are the two relevant measures of access and only proportional measure was included in the study. Lastly, the income measure does not take into account satellite families, where a member of the household is contributing a substantial amount of money to support the family from working abroad. In this case, these households would still be classified as low-income households in Canada, but they actually belong to a higher income group.

\section{Knowledge Translation}


The key message conveyed from this study is that public access to existing green space and parks should be protected due to the many benefits it can provide to all neighbourhoods, especially to a low-income neighbourhood. The World Health Organization recommends that, every city should provide each person with access to a minimum of 9 square meters of green space (WHO, 2010). Green space is very important component of a healthy built environment and it cannot be overemphasized that every individual should have enough access to it regardless of their socio economic status. As such, this calls for policy makers and city planners to have higher investment in green space and recreational park initiatives in existing and developing neighbourhoods. The best public health intervention here is for planners and policy makers is to make green space availability stronger even in moderately wealthy neighbourhoods.

\section{Future Research}

Based on this study, several future research project ideas for students can be suggested:

- Previous studies suggest that lower income neighbourhoods often had access to lower quality parks. This warrants a new study, comparing social economic status within Vancouver and access to quality of parks. This is a study that will require GIS knowledge.

- A study which consist of a survey looking at if having more greenspace available equates to the utilization of greenspace.

- A study which consists of a survey to determine whether utilization of greenspace and public recreational parks vary among different social economic classes

\section{Conclusion}

Green space is undeniably important to all individuals within a city as it can provide recreational opportunities, improve physical and mental health, temper climate change, improve air quality and provide cooling effects. This study showed that higher income census tracts have less access to green space. No other studies found in the literature have produced similar findings. Overall, the benefits of greenspace on health have been widely reported, hence if these findings are accurate, then this may benefit those in lower socio-economic strata as it would provide free access to green spaces. 
There may be substitute to recreational activities that green space can provide, but there are none for the overall benefits that it can provide. Thus, this study calls for policy makers and planners to consider greater investments in green space and recreational parks in all census tracts including wealthy ones.

\section{Acknowledgement}

The author would like to acknowledge Helen Heacock for their knowledge and extensive support throughout this project.

\section{Competing Interest}

The author declares that they have no competing interest in this study. 


\section{References}

Luo, D. , Heacock, H. (2020). Access to Greenspace and Median Household Income in Metro Vancouver Cities. BCIT, Environmental Health Journal

Nesbitt, L., Meitner, M. J., Girling, C., Sheppard, S. R., \& Lu, Y. (2019). Who has access to urban vegetation? A spatial analysis of distributional green equity in 10 US cities. Landscape and Urban Planning, 181, 51-79. doi: 10.1016/j.landurbplan.2018.08.007

Centre for Disease Control. Facts about Physical Activity. (2014, May 23). Retrieved November 18, 2019, from https://www.cdc.gov/physicalactivity/data/facts.htm

Gilmour, H. (2007). Physically active Canadians. Health Reports, 18(3), 45-65.

Mytton, O. T., Townsend, N., Rutter, H., \& Foster, C. (2012). Green space and physical activity: An observational study using Health Survey for England data. Health \& Place, 18(5), 1034-1041. doi: 10.1016/j.healthplace.2012.06.003Humphreys, B. R., Mcleod, L., \& Ruseski, J. E. (2014). Physical Activity And Health Outcomes: Evidence From Canada. Health Economics, 23(1), 33-54. doi: 10.1002/hec.2900

Moore, L. V., Roux, A. V. D., Evenson, K. R., Mcginn, A. P., \& Brines, S. J. (2008). Availability of Recreational Resources in Minority and Low Socioeconomic Status Areas. American Journal of Preventive Medicine, 34(1), 16-22. doi: 10.1016/j.amepre.2007.09.021Bowler, D. E., Buyung-Ali, L. M., Knight, T. M., \& Pullin, A. S. (2010). A systematic review of evidence for the added benefits to health of exposure to natural environments. BMC Public Health, 10(1). doi: 10.1186/1471-2458$10-456$

Richardson, E., Pearce, J., Mitchell, R., \& Kingham, S. (2013). Role of physical activity in the relationship between urban green space and health. Public Health, 127(4), 318-324. doi: 10.1016/j.puhe.2013.01.004

Gladwell, V. F., Brown, D. K., Wood, C., Sandercock, G. R., \& Barton, J. L. (2013). The great outdoors: how a green exercise environment can benefit all. Extreme Physiology \& Medicine, 2(1). doi: 10.1186/2046-7648-2-3

Bell, Simon et al. (2008). Greenspace and quality of life: a critical literature review: Research report. Stirling, Scotland: Greenspace Scotland.

Handy, S. L., Boarnet, M. G., Ewing, R., \& Killingsworth, R. E. (2002). How the built environment affects physical activity. American Journal of Preventive Medicine, 23(2), 64-73. doi: 10.1016/s0749-3797(02)00475-0

Lemstra, M., Neudorf, C., \& Opondo, J. (2006). Health Disparity by Neighbourhood Income. Canadian Journal of Public Health, 97(6), 435-439. doi: 10.1007/bf03405223 
WHO. Urban green spaces. (2016, August 4). Retrieved from https:/www.who.int/sustainabledevelopment/cities/health-risks/urban-green-space/en/.

Statistics Canada. (2016). Table 38-10-0022-01 Parks and green spaces, by household income.

Barton, J., \& Rogerson, M. (2017). The importance of greenspace for mental health. BJPsych international, 14(4), 79-81.

Lee, S. A., Ju, Y. J., Lee, J. E., Hyun, I. S., Nam, J. Y., Han, K.-T., \& Park, E.-C. (2016). The relationship between sports facility accessibility and physical activity among Korean adults. BMC Public Health, 16(1). doi: 10.1186/s12889-016-3574-z

Jennings, V., \& Bamkole, O. (2019). The Relationship between Social Cohesion and Urban Green Space: An Avenue for Health Promotion. International Journal of Environmental Research and Public Health, 16(3), 452. doi: 10.3390/ijerph16030452

Greenest City: 2020 Action Plan, 2014-2015 Implementation Update (2014). The City of Vancouver. URL: http://vancouver.ca/files/cov/greenest-city-action-planimplementation-update-2014-2015.pdf Accessed: April 10, 2016.

Zupancic, T. (2015). The impact of green space on heat and air pollution in urban communities: a meta-narrative systematic review. Vancouver, BC: David Suzuki Foundation.

Statistics Canada. (2019, July 17). Census Profile, 2016 Census. Retrieved from https://www12.statcan.gc.ca/census-recensement/2016/dp-pd/prof/index.cfm?Lang=E.

Luo . Y., Gee, H., \& Nicole, A. (2018). Proportions of Visible Minority and Green space. Unpublished student project, Simon Fraser University, British Columbia, Canada.

Urban planning, environment and health: from evidence to policy action. (2017, March 18). Retrieved from http://www.euro.who.int/en/health-topics/environment-andhealth/Housing-and-health/publications/2010/urban-planning,-environment-and-healthfrom-evidence-to-policy-action 